\title{
A hybrid approach of remote sensing for mapping vegetation biodiversity in a tropical rainforest
}

\author{
WAHYU WARDHANA ${ }^{1, \boldsymbol{v}}$, WIRASTUTI WIDYATMANTI ${ }^{2}$, EMMA SORAYA ${ }^{1}$, DJOKO SOEPRIJADI ${ }^{1}$, \\ BEKTI LARASATI ${ }^{1}$, DEHA AGUS UMARHADI ${ }^{2}$, YAASIIN HENDRAWAN TRI HUTOMO ${ }^{1}$, \\ FAHMI IDRIS ${ }^{3}$, PANDU YUDHA ADI PUTRA WIRABUANA ${ }^{1}$ \\ ${ }^{1}$ Department of Forest Management, Faculty of Forestry, Universitas Gadjah Mada. Jl. Agro No.1 Bulaksumur, Sleman 55281, Yogyakarta, Indonesia \\ Tel./fax.: +62-274-548815, `email: wwardhana@ugm.ac.id \\ ${ }^{2}$ Department of Geographic Information Science, Faculty of Geography, Universitas Gadjah Mada. Jl. Sekip Utara, Bulaksumur, Sleman 55281, \\ Yogyakarta, Indonesia \\ ${ }^{3}$ Department of Research and Development, Trofsit. Jl. Sokonilo No. 3, Sidoluhur, Godean, Sleman 55264, Yogyakarta, Indonesia
}

Manuscript received: 17 June 2020. Revision accepted: 5 August 2020.

\begin{abstract}
Wardhana W, Widyatmanti W, Soraya E, Soeprijadi D, Larasati B, Umarhadi DA, Hutomo YHT, Idris F, Wirabuana PYAP. 2020. A hybrid approach of remote sensing for mapping vegetation biodiversity in a tropical rainforest. Biodiversitas 21: $3946-3953$. Vegetation biodiversity is one of the most important indicators to evaluate the sustainability of tropical rainforest. It is commonly described by three essential variables, i.e. richness, heterogeneity, and evenness. That information is frequently collected from periodic forest inventory using terrestrial method. However, this effort needs a long-time consuming, high cost, and almost impossible to implement in the area of tropical rainforest with hard accessibility. This study investigates the potential of remote sensing as an alternative method for mapping vegetation biodiversity in a tropical rainforest. A hybrid approach of remote sensing using medium and high-resolution images was developed to recognize the attributes of vegetation biodiversity by considering three parameters derived from remote sensing data, including canopy density (C), crown diameter (D), and tree density (N). The use of a medium resolution image aimed to categorize vegetation density using Modified Soil-Adjusted Value Index (MSAVI) while a high-resolution image was utilized to acquire a more detailed spectrum for determining $\mathrm{C}, \mathrm{D}$, and $\mathrm{N}$ in every class of vegetation density. The relationship between $\mathrm{C}, \mathrm{D}, \mathrm{N}$, and richness, heterogeneity, evenness was explained using hierarchical cluster analysis. Our study discovered the at tributes of vegetation biodiversity in a tropical rainforest could be potentially recognized by combining $\mathrm{C}, \mathrm{D}$, and $\mathrm{N}$ as predictor variables.
\end{abstract}

Keywords: forest inventory, hierarchical cluster, hybrid remote sensing, tropical rainforest, vegetation biodiversity

\section{INTRODUCTION}

Sustainable forest management (SFM), particularly in the tropical rainforest area, becomes an important issue in many countries, including Indonesia. This effort requires an amount of data and information related to forest attributes such as stand structure, species composition, vegetation biodiversity, soil properties, and timber volume as the basis of planning determination (Castillo-Santiago et al. 2010). Among those attributes, vegetation biodiversity is one of the main indicators to evaluate the balance of ecosystem in the tropical rainforest (Naidu \& Kumar 2016). Moreover, it can also be used to assess the success of natural regeneration (Khaine et al. 2018).

The availability of data and information about vegetation biodiversity in a tropical rainforest is regularly obtained from periodic forest inventory (Pocock et al. 2015). It is the principal obligation for every manager, especially in Indonesia. This activity must be conducted periodically, one a time in ten years to monitor the dynamics of forest ecosystems, regarding wood production and natural regeneration. Most importantly, the use of periodic forest inventory also aims to identify the endangered tree species which should be conserved immediately. Unfortunately, the activity of forest inventory using field surveys generally requires high cost, long-time consuming, and almost impossible to conduct in the forest area with great environmental gradient (Sibona et al. 2017). Consequently, this approach is not capable to measure vegetation biodiversity for those areas which are not surveyed directly due to the hard accessibility. In another side, comprehensive information about vegetation biodiversity is very required for long-term forest planning. To answer this challenge, the use of remote sensing may have a potential for supporting periodic forest inventory in a tropical rainforest, particularly to recognize vegetation biodiversity, including richness, heterogeneity, and evenness.

Several literature has documented the advantage of remote sensing for supporting forest inventory. A study done by Bergseng et al. (2015) in the boreal forest, Norwegia reports the application of remote sensing for forest inventory requires lower cost and more efficient time than conducting field surveys. Another study conducted by Dash et al. (2016) in Pinus radiata plantation, New Zealand explains the utilization of remote sensing can also observe the forest area located in site with low accessibility. Furthermore, a study was undertaken by Liu et al. (2017) in subtropical forest, China demonstrates that the activity of data collection using remote sensing is 
possible carried out periodically and capable to detect the forest disturbance earlier. It also has been obviously recorded in the previous studies the use of remote sensing is helpful to estimate forest attributes, such as diameter at breast height in natural forest, Mongolia (Liu et al. 2018); basal area of Oak forest in western Iran (Ghahramany et al. 2012); and aboveground biomass of subtropical forest in China (Du et al. 2014). Similarly to those studies, the use of remote sensing also provides good accuracy for facilitating forest inventory in the tropical rainforest. A study conducted by Margono et al. (2012) demonstrates that the use of remote sensing has a potential contribution to monitoring forest degradation periodically in tropical rainforest, Indonesia. Another study was done by Mitchell et al. (2017) documents that remote sensing is useful to assess carbon storage dynamics of tropical rainforest in Indonesia, Vietnam, Malaysia, and Brazil. However, the accuracy of data derived from remote sensing relatively varies depending on type of forest, images resolution, weather, and selected method (Mauya et al. 2015).

This study investigates the potential of remote sensing as an alternative method for assessing vegetation biodiversity in a tropical rainforest. A hybrid approach of remote sensing using two different images resolution, namely medium and high, is constructed to identify vegetation biodiversity, covering richness, heterogeneity, and evenness, with specific attributes. We proposed a hybrid approach of remote sensing to obtain more detailed spectrum for assessing the vegetation condition of tropical rainforest which grew in the various environmental gradient. In this case, the use of medium resolution images was directed to identify the environmental gradient in tropical rainforests while the utilization of high-resolution images aimed to derive more detailed visualization for assessing vegetation performance. We suppose the vegetation biodiversity in a tropical rainforest can be recognized from remote sensing data.

\section{MATERIALS AND METHODS}

\section{Study area}

This study was conducted in a tropical rainforest, located in East Borneo Province, Indonesia. The geographic positions of this site were $00^{0} 34^{\prime}$ to $00^{0} 55^{\prime} \mathrm{N}$ and $115^{\circ} 10^{\prime}$ to $115^{0} 34^{\prime} \mathrm{E}$ (Figure 1 ). It was managed by a private company with a total concession area of approximately 54,405 ha. The effective area for timber production was around 30,730 ha or equivalent to $56.48 \%$ of total managed area. This site had humid condition with air humidity ranging from 81 to $86 \%$. The average daily temperature was $27.1{ }^{\circ} \mathrm{C}$ with a mean minimum of $24.3{ }^{\circ} \mathrm{C}$ and an average maximum of $29.9{ }^{\circ} \mathrm{C}$. Annual rainfall during the last 10 years from 2000 to 2010 reached 2,180 mm year ${ }^{-1}$. Topography was relatively flat with slope level varying from 0 to $8 \%$. The majority of vegetation in the study area was dominated by family Dipterocarpaceae, consisting of Shorea sp., Hopea sp., and Dryobalanops sp.

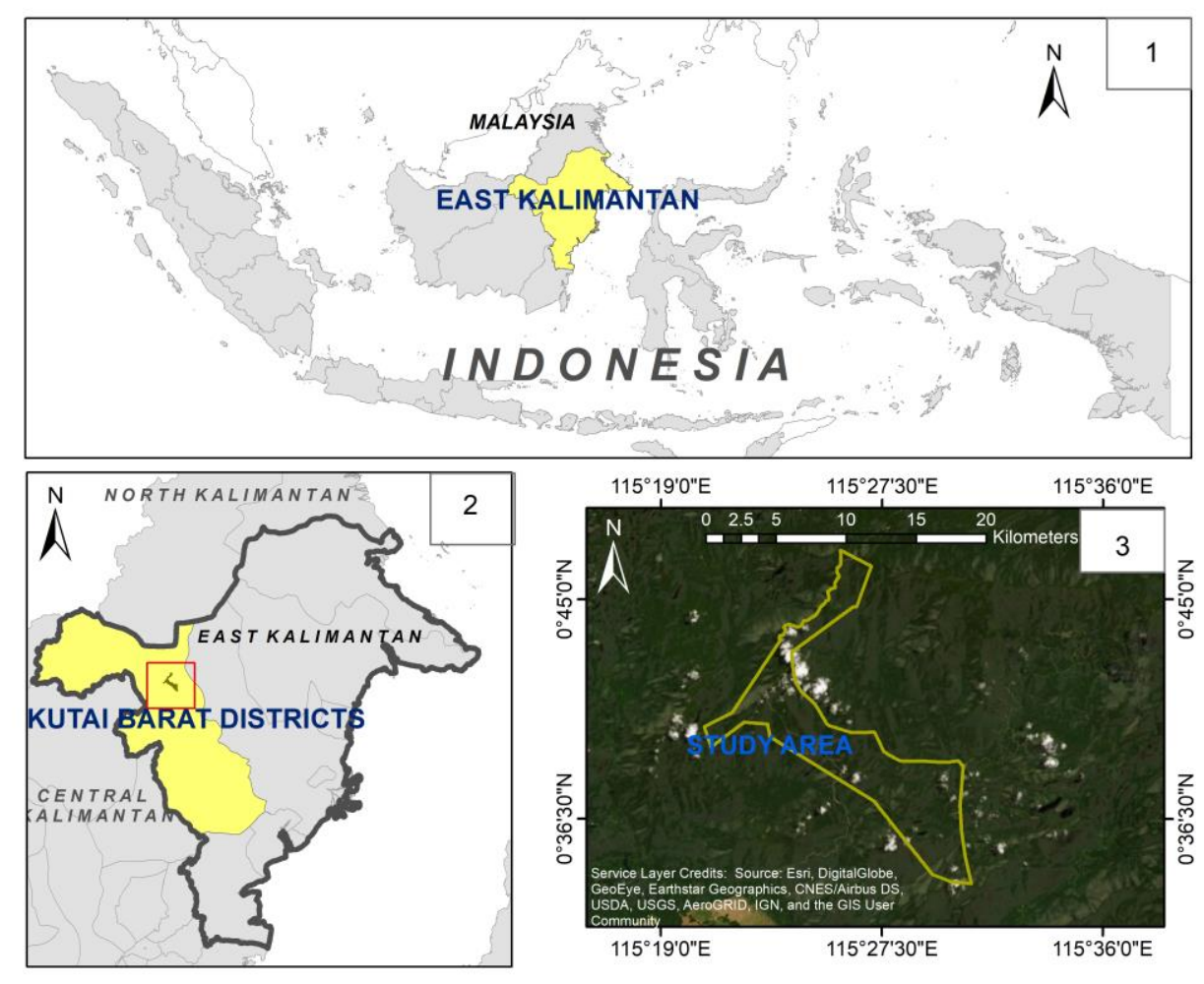

Figure 1. Study area in a tropical rainforest concession, located in East Borneo Province, Indonesia 


\section{Data collection}

A hybrid approach of remote sensing was constructed to recognize vegetation biodiversity in the study area, including richness, heterogeneity, and evenness. The term hybrid was reviewed from the combination of two different images used to obtain remote sensing data, namely medium and high resolutions. This approach was relatively similar to multi-stage remote sensing which combined several images with having different resolutions. The utilization of a medium resolution image aimed to classify vegetation density using Modified Soil-Adjusted Index (MSAVI). This index was used since it could minimize the effect of soil on vegetation signal (Noorian et al. 2016). It was helpful to reduce the bias of interpretation related to vegetation conditions due to the impacts of environmental aspects, particularly from soil conditions. The assessment of MSAVI was carried out by the correction process of radiometric and geometry on LANDSAT 8 (Zhang et al. 2019). Afterward, MSAVI was calculated using vegetation index transformation by following the equation (Meng et al. 2016):

$$
\text { MSAVI = (NIR-Red }) /(\mathrm{NIR}+\mathrm{RED}+\mathrm{L}) \times(\mathrm{I}+\mathrm{L})
$$

Where; NIR was the near-infrared band reflectance, RED stated the red band reflectance from a sensor, and $\mathrm{L}$ indicated the soil brightness correction factor. The outcome of MSAVI would show a number of variation that was assumed to represent the gradient of vegetation in a tropical rainforest. Afterward, it would be categorized into several classes by considering the data range. Next, the number of sampling plots was placed proportionally in every MSAVI category. Total sampling plot of this study was about 166 units. Every sampling plot had a squared design with its size around $200 \mathrm{~m} \times 200 \mathrm{~m}$.

After the distribution of sampling plots have been clearly determined, a high-resolution image was selected to derive a more detailed spectrum (WORLDVIEW-3). It was directed to assess the vegetation attributes from remote sensing data, i.e. canopy density (C), crown diameter (D), and tree density $(\mathrm{N})$. This process was undertaken by object-based approach (Figure 2). It was a conventional method where an object was quantified in a specific size (Blaschke 2010). In this case, the specific size for image interpretation referred to the size of sampling plot. Moreover, a supervised multi-spectral classification using super vector machine (SVM) method was adopted to estimate canopy density (Xie et al. 2019) while crown diameter was computed based on the image interpretation by relatively crown size (Wagner et al. 2018). A similar technique was also applied to predict tree density by observing shape, texture, and color (Fadaei et al. 2010). Then, the vegetation survey by field survey was carried out to record the type of species and their actual density.

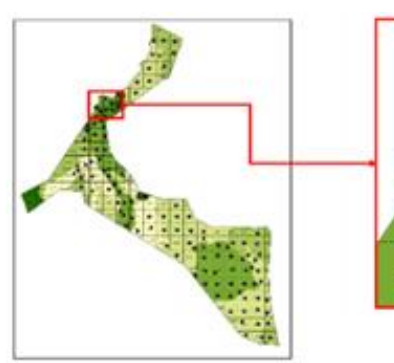

1

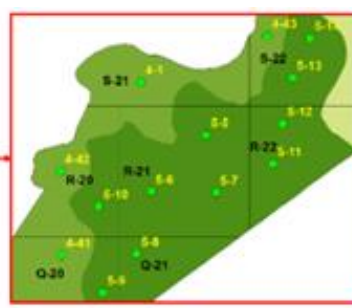

2

Description:

1. Sample distribution per stand class

2. Sample distribution in compartments. Yellow text is sample's number and black text is compartment's number

3. Build a cluster sized $200 \times 200 \mathrm{~m}$ for each sample plots. Divide the cluster into 4 sub clusters.

4. Add high resolution imagery in every cluster

5. A clip of high resolution image in compartment $\mathrm{R}-22$ and plot number 5-11. A cluster comprises of 4 sub clusters namely sub cluster $1,2,3$, and 4 .

6. $\mathrm{C} \%$ classification result based on Super Vector Machine (SVM) method

7. Tree density calculation results from $1^{\text {st }}$ repetition

8. Tree density calculation results from $2^{\text {nd }}$ repetition

9. Crown diameter calculation results

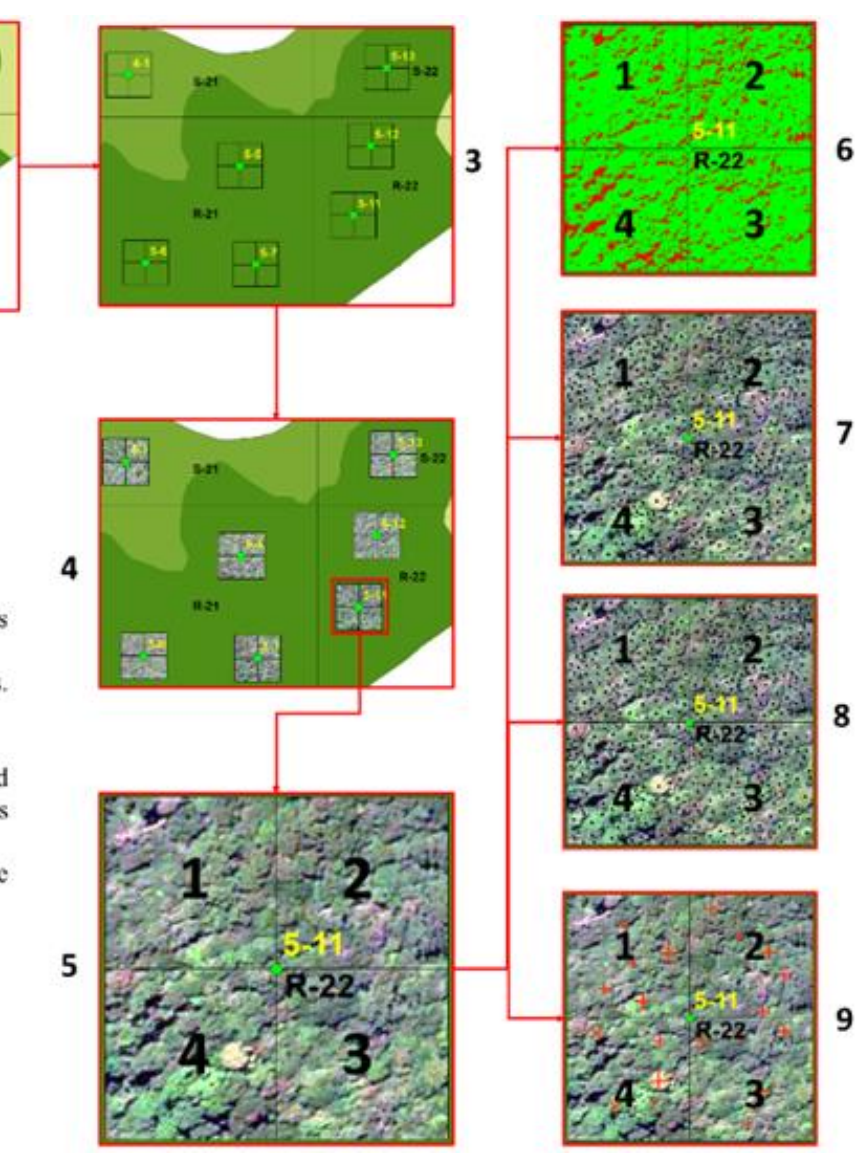

Figure 2. Detail protocol for interpretation of image attributes using a hybrid approach of remote sensing 


\section{Data analysis}

Assessment of vegetation biodiversity in the study site was measured by three indicators, i.e. richness, heterogeneity, and evenness. Those indicators were frequently selected to describe plant biodiversity in many types of forest ecosystems (Pocock et al. 2015; Naidu \& Kumar 2016). Richness was calculated by Margalef index $(R I)$ while heterogeneity was computed using ShannonWiener index $\left(H^{\prime}\right)$. In another side, evenness was counted by Pielou index $(E)$. Detail equation of every indicator was expressed below:

$$
\begin{aligned}
& \mathrm{R} 1=\mathrm{S}-1 / \ln (\mathrm{N}) \\
& \mathrm{H}^{\prime}=-\sum(\mathrm{ni} / \mathrm{N} \mathrm{x} \ln \mathrm{ni} / \mathrm{N}) \\
& \mathrm{E}=\mathrm{H}^{\prime} / \ln (\mathrm{S})
\end{aligned}
$$

Where $S$ was a number of species observed, $N$ described total plant population, and $n i$ represented a number population of every species. Next, the attributes of vegetation biodiversity would be classified into three groups by considering their data ranges, consisting of low, medium, and high. Furthermore, we also applied a hierarchical cluster analysis to evaluate the different categories of $\mathrm{C}, \mathrm{D}$, and $\mathrm{N}$ in every vegetation class which has been categorized by MSAVI. In this context, we tried to identify the relationship between $\mathrm{C}, \mathrm{D}, \mathrm{N}$, and richness, heterogeneity, evenness in each vegetation class (Figure 3).

\section{RESULTS AND DISCUSSION}

Classification of vegetation density became the first stage of forest inventory using remote sensing since it could help to describe the environmental gradient in the tropical rain forest. Summarized results of the observation clearly demonstrated the different vegetation conditions in the study area. According to the outcome of MSAVI values, we classified the vegetation density into three groups, namely low $(<0.30)$, medium $(0.31-0.50)$, and high $(>0.51)$. The majority area of study site was occupied by a medium vegetation class, only a few areas were categorized as low and high vegetation class (Figure 4). These results indicated that most of area in the study site had similar conditions relatively, reviewed from the vegetation density.

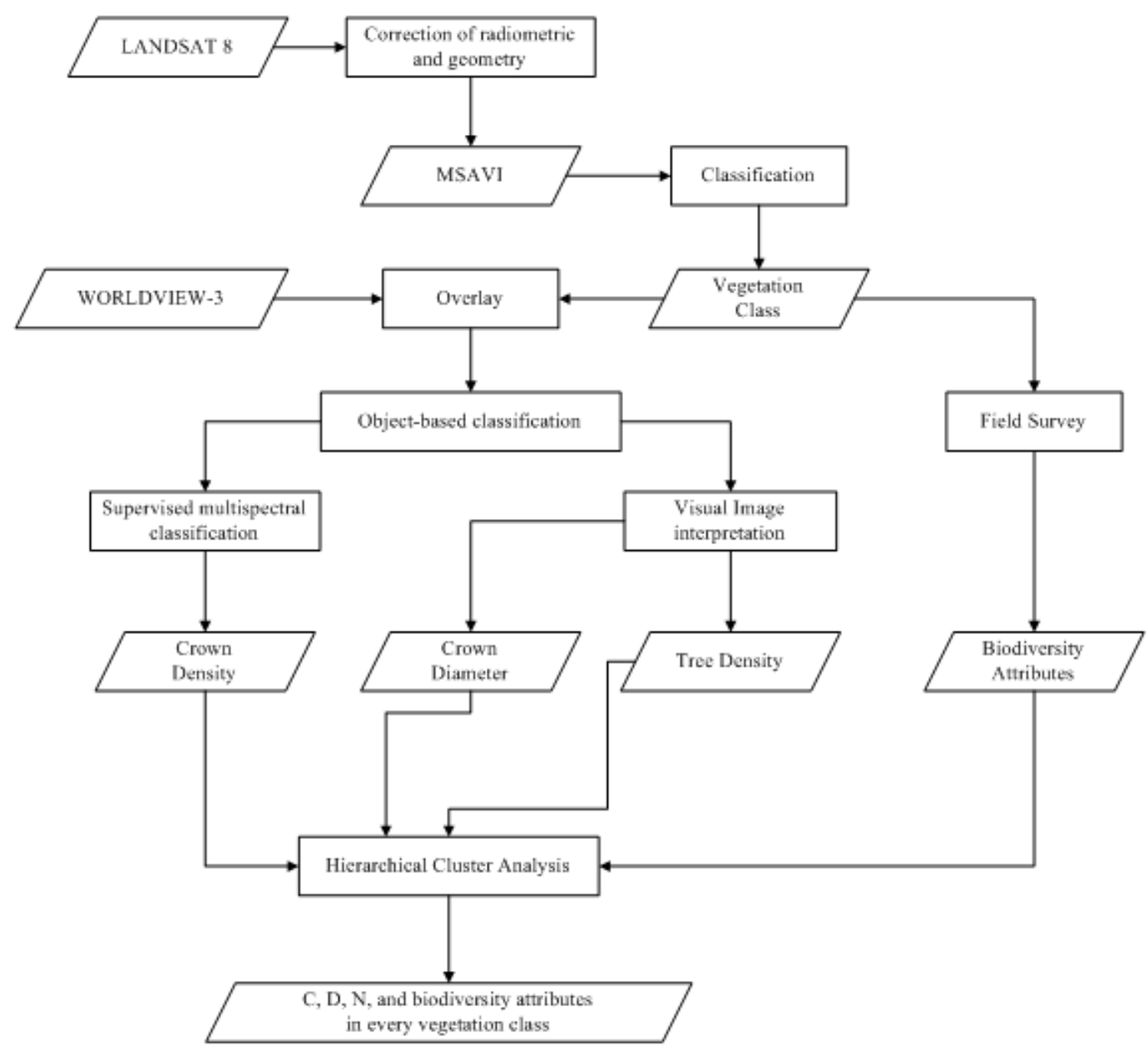

Figure 3. Flow process in a hybrid approach of remote sensing using medium and high resolution image for assessing vegetation biodiversity in a tropical rainforest 
Several different types of stratification were used to group canopy density (C), crown diameter (D), and tree density $(\mathrm{N})$. In this study, four different categories were selected to stratify canopy density, i.e. C1 (10-30\%), C2 $(31-50 \%), \mathrm{C} 3(51-70 \%)$, and C4 $(>70 \%)$ (Figure $5 \mathrm{a})$. While, the classification of crown diameter was conducted using three groups, including D1 (<10 m), D2 (10-20 m), and D3 $(>20 \mathrm{~m})$ (Figure 5b). We used three distinct classes to organize three density, namely N1 $(<100), \mathrm{N} 2(100-$ 200 ), and N3 (>200) (Figure 5c). Our study revealed there were only two categories of canopy density in the study site, i.e. C3 and C4. More than $80 \%$ of area had dense canopy and were categorized into $\mathrm{C} 4$. Meanwhile, a complete classification was showed by crown diameter and tree density (Figure 5). Based on these outcomes, this study noted eight combinations of $\mathrm{C}, \mathrm{D}$, and $\mathrm{N}$ parameters to identify the pattern of vegetation biodiversity in the tropical rainforest (Table 1).

Table 1. Combination of $\mathrm{C}, \mathrm{D}$, and $\mathrm{N}$ for assessing vegetation biodiversity in the tropical rainforest

\begin{tabular}{lcl}
\hline CDN categories & $\begin{array}{c}\text { Mean of } \\
\text { MSAVI }\end{array}$ & $\begin{array}{l}\text { MSAVI } \\
\text { category }\end{array}$ \\
\hline C3D1N1 & 0.460 & Medium \\
C3D1N2 & 0.470 & Medium \\
C4D1N1 & 0.433 & Medium \\
C4D1N2 & 0.429 & Medium \\
C4D1N3 & 0.440 & Medium \\
C4D2N1 & 0.443 & Medium \\
C4D2N2 & 0.411 & Medium \\
C4D3N1 & 0.336 & Medium \\
\hline
\end{tabular}

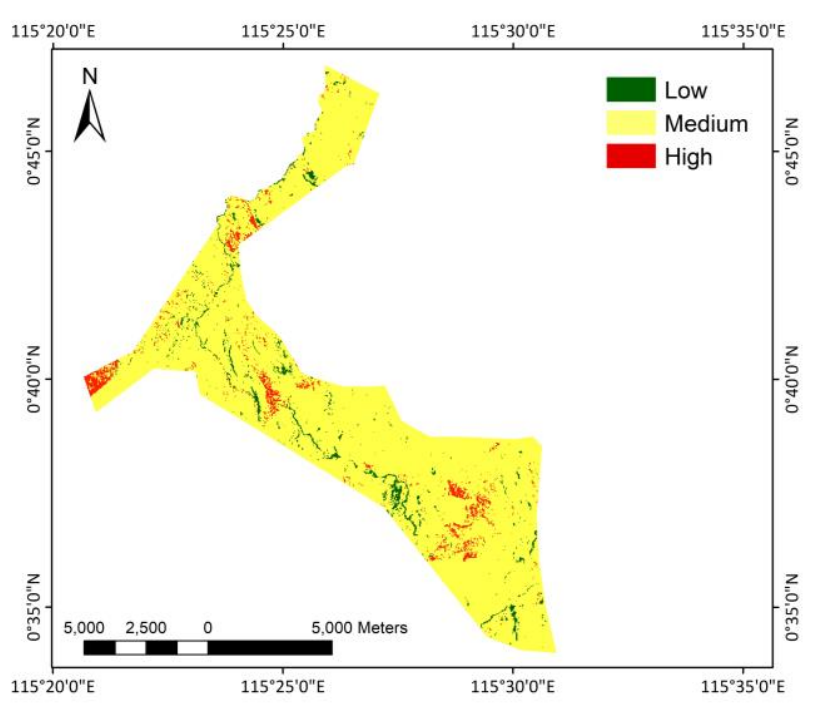

Figure 4. Classification of vegetation density in the tropical rainforest using MSAVI data range from LANDSAT 8
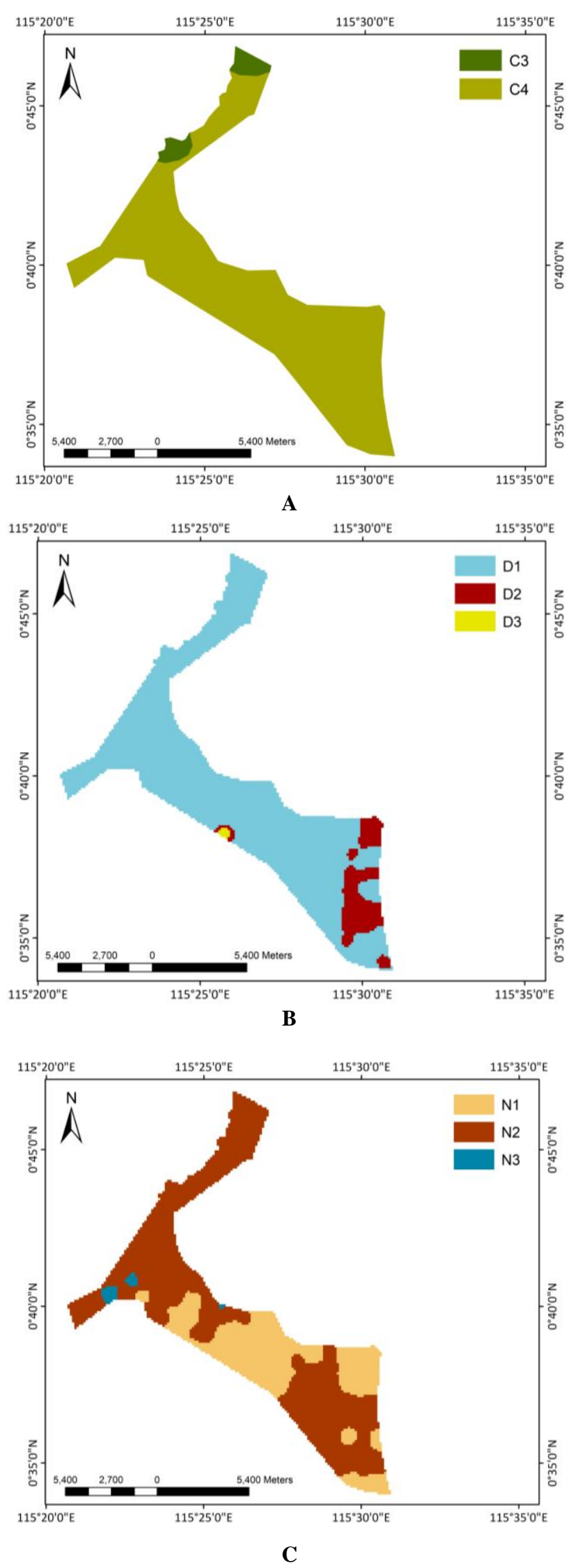

Figure 5. Distribution of (a) canopy density, (b) crown diameter, (c) tree density using high-resolution image WORLDVIEW-3 
Vegetation biodiversity was reviewed from three aspects, namely richness, heterogeneity, and evenness. We used three categories to classify those attributes, namely low, medium, and high based on the range values of every criterion. Results demonstrated the richness was classified into low (0.5-1.0), medium (>1.0-2.0), and high $(>2.0)$ while heterogeneity was categorized as low $(<1.5)$, medium (1.5-3.5) and high (>3.5). In another side, evenness was also grouped into low (0.1-0.3), medium (>0.3-0.6), and high (>0.6). Our study observed the distribution of vegetation biodiversity was dominated by medium class. However, there were several areas that had vegetation biodiversity in low and medium classes (Figure 6). Interestingly, after the outcome of vegetation density was combined with vegetation biodiversity, it was clearly seen that the mean of richness, evenness, and heterogeneity in every vegetation density class was equal relatively (Table 2 ). But, the number of species in each class was slightly different wherein total species in high class was greater than low class. This study found the combination of CDN had the potential to recognize the pattern of vegetation biodiversity in the study site (Table 3 ). Three different clusters were constructed with the specific combinations of $\mathrm{CDN}$ that indicated the pattern of vegetation biodiversity.

Our study reported the utilization of a medium resolution image had a potential to identify the vegetation biodiversity in the tropical rainforest but it still showed uncertainty outcomes since the variation of vegetation gradient was looked similar. We supposed that the high vegetation density with mixed plant species became the main factor that influenced the low precision of medium image interpretation. Several studies also recorded the identical results where the process classification of stand productivity in the tropical rainforest with a medium resolution image showed a homogenous condition relatively ( $\mathrm{Li}$ et al. 2011; Häme et al. 2013; Noorian et al. 2016). Therefore, many studies suggested examining the capability of a high-resolution image for mapping vegetation biodiversity in the tropical rain forest (Jusoff \& Ibrahim 2009; Kim et al. 2011; Wagner et al. 2018). This study recorded the application of a high-resolution image with CDN combination provided better outcomes to identify the pattern of vegetation biodiversity in the tropical rain forest. It was obviously demonstrated where every category of vegetation biodiversity had different CDN attributes.

Our study revealed that using a high-resolution image was more capable to map the attributes of a tropical rain forest than a medium resolution image. It is attributed to a more detailed spectrum for identification of the vegetation characteristics (Fadaei et al. 2010; Kim et al. 2011), such as canopy density, crown diameter, and tree density. Nevertheless, the use of a medium resolution image could still be used as an option for forest inventory in the tropical rain forest by considering a better spectral resolution (Jusoff \& Ibrahim 2009). Moreover, using a medium resolution image with different types of vegetation index might have the potential to identify the stand productivity in the tropical rain forest (Miettinen et al. 2014). Then, we encourage to conduct another study about the use of hybrid remote sensing with the combination of medium and highresolution images to recognize the pattern of vegetation biodiversity in other sites of tropical rainforest as replications for validating this method.

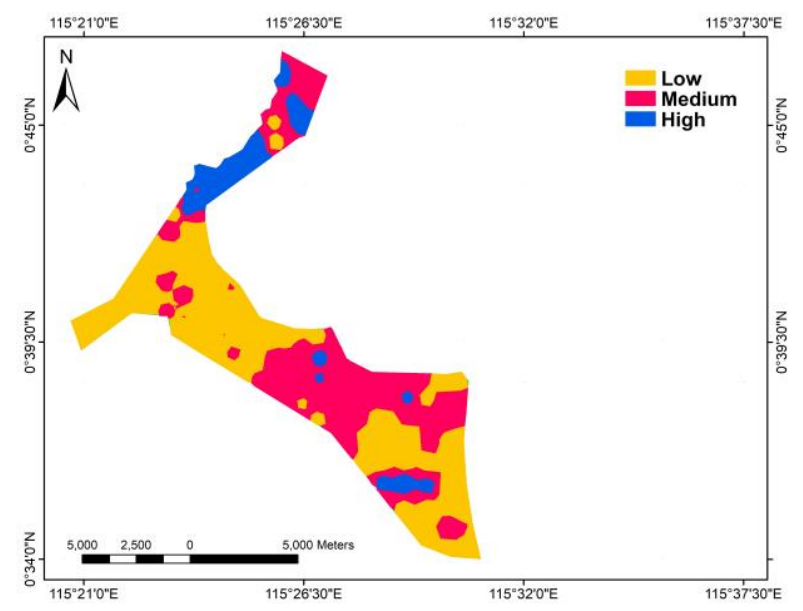

A
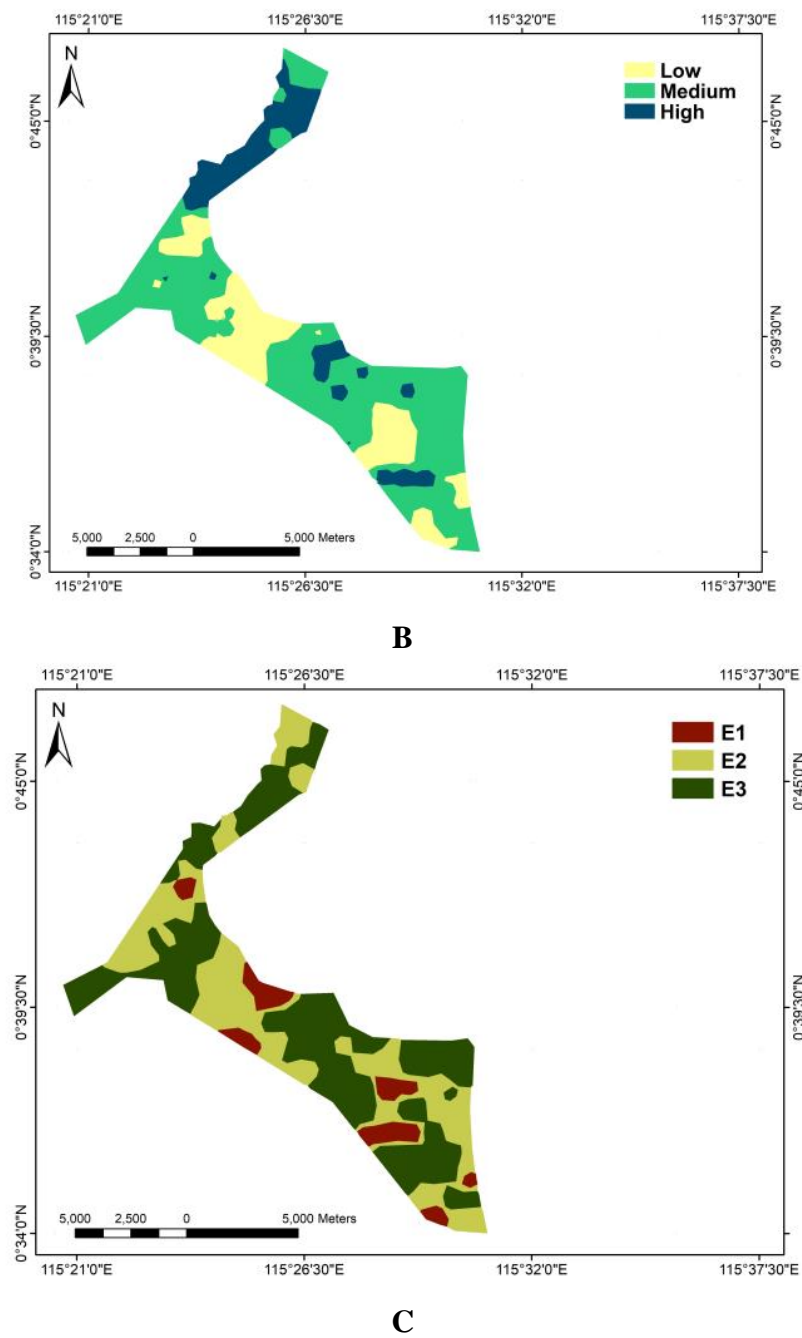

Figure 6. Distribution of (A) richness, (B) heterogeneity, and (C) evenness in the tropical rainforest as study area 
Table 2. Mean of richness, heterogeneity, and evenness in every vegetation class

\begin{tabular}{llllll}
\hline Clusters & S & E & H' & MSAVI & CDN \\
\hline 1 & 1.11 & 0.76 & 1.15 & Low & C3D1N2, C4D1N1, \\
& & & & & C4D1N3 \\
2 & 1.19 & 0.73 & 1.19 & Medium & C3D1N1, C4D1N2, \\
3 & 1.30 & 0.63 & 1.17 & High & C4D2N1 \\
3 & & & & &
\end{tabular}

In the context of tropical rainforest management, particularly in Indonesia, every forest managers have an obligation to conduct periodic forest inventory in every 10 years. This activity commonly needs high cost and longtime consuming since it covers a large area with great environmental gradient. In fact, there are many forest sites which not surveyed due to the hard accessibility. Consequently, the majority of forest managers in tropical rainforest can not determine the best planning for supporting sustainable forest management. By using hybrid remote sensing, we expect the implementation of periodic forest inventory in tropical rainforest became better wherein since it can observe overall concession areas including sites with having low accessibility.

In conclusion, this study concluded that using a hybrid approach of remote sensing for tropical rainforest inventory was potentially able to identify vegetation biodiversity in a tropical rainforest by adopting three specific indicators, including canopy density, crown diameter, and tree density. Therefore, the use of this approach could be considered as an option method for periodic forest inventory in the tropical rainforest.

\section{ACKNOWLEDGEMENTS}

This study was funded by RTA-UGM 2019 through a grant received by Dr. Wahyu Wardhana. Authors are very grateful to PT. Daya Maju Lestari allows us to conduct this study as the part of activity for periodic forest inventory in their tropical rainforest concession area. We also deliver our gratitude to reviewers for their suggestions to this article.

\section{REFERENCES}

Bergseng E, Ørka HO, Næsset E, Gobakken T. 2015. Assessing forest inventory information obtained from different inventory approaches and remote sensing data sources. Ann For Sci 72 (1): 33-45. DOI: $10.1007 / \mathrm{s} 13595-014-0389-\mathrm{x}$

Blaschke T. 2010. Object-based image analysis for remote sensing. ISPRS Journal of Photogrammetry and Remote Sensing 65 (1): 2-16. DOI: 10.1016/j.isprsjprs.2009.06.004

Castillo-Santiago MA, Ricker M, De Jong BHJ. 2010. Estimation of tropical forest structure from spot-5 satellite images. Int J Remote Sens 31 (10): 2767-2782. DOI: 10.1080/01431160903095460

Dash J, Pont D, Watt MS, Dash J, Pont D, Brownlie R, Pearse G. 2016. Remote sensing for precision forestry. N Z J For 60 (4): 15-24.

Du L, Zhou T, Zou Z, Zhao X, Huang K, Wu H. 2014. Mapping forest biomass using remote sensing and national forest inventory in China. Forests 5 (6): 1267-1283. DOI: 10.3390/f5061267.
Fadaei H, Sakai T, Yoshimura T, Kazuyuki M. 2010. Estimation of tree density with high-resolution imagery in the Zarbin forest of North Iran (Cupressus sempervirence var. horzontalis). Intl Arch Photogram, Rem Sens Spat Inform Sci 38 (8): 679-684.

Ghahramany L, Fatehi P, Ghazanfari H. 2012. Estimation of basal area in west oak forests of Iran using remote sensing imagery. Intl J Geosci 3 (2): 398-403. DOI: 10.4236/ijg.2012.32044

Häme T, Kilpi J, Ahola HA, Rauste Y, Antropov O, Rautiainen M, et al. 2013. Improved mapping of tropical forests with optical and SAR imagery, part i: Forest cover and accuracy assessment using multiresolution data. IEEE J Selec Topics Appl Earth Observ Rem Sens 6 (1): 74-91. DOI: $10.1109 /$ JSTARS.2013.2241019

Jusoff K, Ibrahim K. 2009. Hyperspectral remote sensing for tropical rain forest. Am J Appl Sci 6 (12): 2001-2005. DOI: 10.3844/ajassp.2009.2001.2005

Khaine I, Woo SY, Kwak M, Lee SH, Je SM, You H, Kim J. 2018. Factors affecting natural regeneration of tropical forests across a precipitation gradient in Myanmar. Forests 9 (3): 1-17. DOI: 10.3390/f9030143

Kim SR, Lee WK, Kwak DA, Biging GS, Gong P, Lee JH, Cho HK. 2011. Forest cover classification by optimal segmentation of highresolution satellite imagery. Sensors 11 (2): 1943-1958. DOI: $10.3390 / \mathrm{s} 110201943$

Li G, Lu D, Moran E, Hetrick S. 2011. Land-cover classification in moist tropical region Brazil with Landsat TM imagery. Intl J Rem Sens 32 (23): 8207- 8230. DOI: 10.1080/01431161.2010.532831.

Liu C, Xing Y, Duanmu J, Tian X. 2018. Evaluating different methods for estimating diameter at breast height from terrestrial laser scanning. Rem Sens 10 (4): 1-20. DOI: 10.3390/rs10040513

Liu S, Wei X, Li D, Lu D. 2017. Examining forest disturbance and recovery in the subtropical forest region of Zhejiang Province using Landsat time-series data. Rem Sens 9 (5): 1-16. DOI: $10.3390 / \mathrm{rs} 9050479$

Margono AB, Turubanova S, Zhuravlera I, Potapov P, Tyukavina A, Baccini A, Goetz S, Hansen MC. 2012. Mapping and monitoring deforestation and forest degradation in Sumatra (Indonesia) using Landsat time-series data sets from 1990 to 2010. Environ Res Lett 7 (3): 1-17. DOI: 10.1088/1748-9326/7/3/034010

Mauya EW, Hansen EH, Gobakken T, Bollandsås OM, Malimbwi RE, Næsset E. 2015. Effects of field plot size on prediction accuracy of aboveground biomass in airborne laser scanning-assisted inventories in tropical rain forests of Tanzania. Carbon Balance Manag 10 (1): 114. DOI: $10.1186 / \mathrm{s} 13021-015-0021-\mathrm{x}$

Meng J, Li S, Wang W, Liu Q, Xie S, Ma W. 2016. Mapping forest health using spectral and textural information extracted from SPOT-5 satellite images. Rem Sens 8 (9): 1-20. DOI: 10.3390/rs8090719

Miettinen J, Stibig HJ, Achard F. 2014. Remote sensing of forest degradation in Southeast Asia-Aiming for a regional view through 5$30 \mathrm{~m}$ satellite data. Global Ecol Conserv 2: 24-36. DOI: 10.1016/j.gecco.2014.07.007

Mitchell AL, Rosenqvist A, Mora B. 2017. Current remote sensing approaches to monitoring forest degradation in support of countries management, reporting and verification (MRV) systems for REDD+. Carbon Balance Manag 12 (9): 1-22. DOI: 10.1186/s13021-0170078-9

Naidu MT, Kumar OA. 2016. Tree diversity, stand structure, and community composition of tropical forests in Eastern Ghats of Andhra Pradesh, India. J. Asia-Pac Biodivers 9 (3): 328-334. DOI: 10.1016/j.japb.2016.03.019

Noorian N, Shataee-Jouibary S, Mohammadi J. 2016. Assessment of different remote sensing data for forest structural attributes estimation in the Hyrcanian forests. For Syst 25 (3): 1-11. DOI: $10.5424 / \mathrm{fs} / 2016253-08682$

Pocock MJO, Newson SE, Henderson IG, Peyton J, Sutherland WJ, Noble DG, Roy DB. 2015. Developing and enhancing biodiversity monitoring programmes: A collaborative assessment of priorities. J Appl Ecol 52 (3): 686-695. DOI: 10.1111/1365-2664.12423.

Sibona E, Vitali A, Meloni F, Caffo L, Dotta A, Lingua E, Garbarino M. 2017. Direct measurement of tree height provides different results on the assessment of LiDAR accuracy. Forests 8 (1): 1-12. DOI: 10.3390/f8010007/

Wagner FH, Ferreira MP, Sanchez A, Hirye MCM, Zortea M, Gloor E, ... Aragão LEOC. 2018. Individual tree crown delineation in a highly diverse tropical forest using very high-resolution satellite images. ISPRS J Photogra Rem Sens 145 (9): 362-377. DOI: 10.1016/j.isprsjprs.2018.09.013 
Xie Z, Chen Y, Lu D, Li G, Chen E. 2019. Classification of land cover, forest, and tree species classes with Ziyuan-3 multispectral and stereo data. Rem Sens 11 (2): 1-27. DOI: 10.3390/rs11020164
Zhang S, Chen H, Fu Y, Niu H, Yang Y, Zhang B. 2019. Fractional vegetation cover estimation of different vegetation types in the Qaidam Basin. Sustainability 11 (3): 1-17. DOI: 10.3390/su11030864. 